\title{
Mobile Multimedia Classroom Construction for Rhythmic Gymnastics Based on APT Teaching Model
}

\author{
https://doi.org/10.3991/ijet.v12i07.7216 \\ Youguo Shi \\ Bengbu Medical College, Bengbu, China \\ shiyouguo1234 @yeah. net \\ Shuqin Chen* \\ Bengbu College, Bengbu, China \\ shiyouguo5886@163.com \\ Haitao Wang \\ Huaibei Normal University, Huaibei, China \\ wanghaitao2513@163.com
}

\begin{abstract}
APT teaching model is an information-based teaching model which includes Assessment, Pedagogy and Technology. It can improve students' learning initiative and autonomous learning ability. In this study, mobile multimedia classroom based on APT teaching model was designed for Rhythmic Gymnastics. With APT teaching model, learners' learning is no longer limited to time and place. It can motivate learners' learning interest and enhance learning efficiency. The mobile multimedia classroom was constructed from three aspects: assessment, pedagogy and technology. The final teaching test shows that, learners are very interested in the teaching mode of mobile multimedia classroom and express a strong wish for such teaching mode. Mobile multimedia classroom for Rhythmic Gymnastics based on APT teaching model has a promising application prospect in actual teaching process.
\end{abstract}

Keywords-APT, mobile multimedia classroom, technology

\section{Introduction}

At present, mobile technology has penetrated in each field of people's life. Mobile learning (m-learning) means digital learning and mobile application technology are combined so that learners can be no longer limited to time and place and motivate their learning interest [1]. Foreign countries pay much more attention to m-learning than China. Some developed regions such as Europe and North America started to study m-learning early. Some typical m-learning resource development projects include Uniwap project of University of Helsinki [2] and M-Learning project subsidized by EU [3]. Abualaish et al. [4] put forward a model to recognize the factors influencing the acceptance of m-learning in universities and to research whether prior experi- 
ence of mobile devices had an impact on the acceptance of m-learning. The data gathered from 174 participants were analyzed with a structural equation model. The results show that performance expectancy, effort expectancy, influence of lecturers, quality of service, and personal innovativeness are significant factors influencing behavioral intention of m-learning application. Anwar et al. [5] introduced a new architecture in a mobile distance learning system in an extended cloud computing environment with mobiles and wireless devices. The results verify that this teaching platform is an effective way to improve learning. Chinese researches on m-learning started late, and the research scale is small. Mobile multimedia classroom is a manifestation pattern of m-learning. Mobile multimedia classroom can achieve educational resource sharing, make teaching resources more informationized. Learners can learn and communicate with teachers through mobile terminal software. Mobile multimedia classroom has the advantage of no time and place limit through combining mobile terminal software and network [6-7].

\section{Research Progress Review}

The methods about learning through mobile terminal software have aroused the attention of researchers. Tian et al. [8] rationally applied APP technology and smartphone in foreign language multimedia teaching. The results show that such mobile multimedia networked foreign language teaching based on APP technology will bring new reform and progress for college foreign language teaching. Zhang [9] designed mobile monitoring module in remote multimedia classroom management system. APP program timing technology was applied in the module, and humanmachine communication was achieved through the motion mode. The experimental results show both teachers and students generally consider such remote multimedia classroom management system is more scientific and simpler, with a wider application range. Currently, the research subjects of mobile education are schools and enterprises.

For a long time, many defects have existed in art major teaching, such as oldfashioned educational concept, lack of innovation and outdated teaching contents. There is no modern content in textbook content, and textbook content fails to update in time. All these result in chaotic content and fuzzy concept. New teaching means are badly needed to reform the current situation and carry out scientific teaching [10]. Knowledge, ability and technology are the essential qualities of art students. In traditional teaching method, it is difficult for teachers to consider theoretical knowledge and technology at the same time, and it is hard for students to grasp key points of technologies. After multimedia is introduced in teaching, teaching richness problem is solved. However, defects still exist in traditional multimedia assisted teaching. For example, it is difficult for teachers to make courseware animation; learners can only learn in the fixed classroom; the problems exist in the communication between learners and teachers. Mobile multimedia classroom can well resolve the above problems. Mobile technology is applied to provide learners with a convenient learning environment. For education workers, animation production is especially important for art 
students. The vivid and visual animation can help learners better under the key points of technologies, but traditional animation production method is tedious and timeconsuming. In learning process, learners have a strong wish to grasp learning initiative and dislike rigid classroom study. Besides, there is a good platform for communications between teachers and students.

For the shortcomings existing in art teaching, a mobile multimedia classroom based on APT teaching model was designed for Rhythmic Gymnastics in this paper. In this design, APT (Assessment, Pedagogy and Technology) teaching model was innovatively applied [11]. Besides, the making method of automatic animation marking was used in internal design. In the form of mobile multimedia classroom, APT teaching mode can establish a scientific and effective assessment system. Thus, learners can become teaching subjects, and their learning initiative can be motivated. Learners are no longer limited to time and place in the learning process, and can well communicate with teachers. Meanwhile, they improve learning efficiency. For animation production problem of education workers, automatic marking method was used in this design. Such method can make animation production process which perplexes education workers automated. Thus, courseware making efficiency improves greatly.

\section{Model Analysis}

Under the trend of educational informationization development, Liu et al. proposed APT teaching model on the basis of summarizing and analyzing predecessors' teaching theories. This model includes three dimensions: assessment, pedagogy and technology . The interaction structure of APT teaching model is shown in Fig.1. Assessment contains diagnostic assessment, instant assessment, e-record assessment, performance assessment, gauge and contract assessment etc. Pedagogy includes classroom teaching method, online teaching, mixed teaching, flipped classroom, researchbased teaching and linked teaching etc. Technical means involve word processor, data analysis software, multimedia presentation software, network social software and virtual reality etc. APT teaching model takes into account of students and learning contents at the same time to optimize classroom teaching and change students' learning mode.

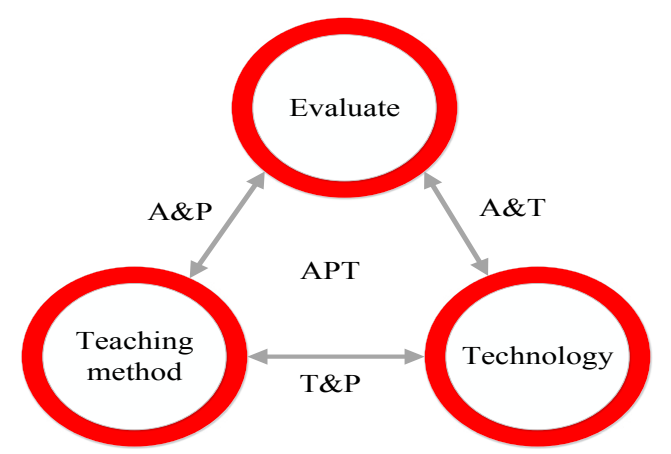

Fig. 1. Entropy value demonstration diagram of land use situation in Xi'an in 1959-2016 
As shown in Fig.2, APT teaching theory is based on comprehensive analysis results of course teaching objective, teaching content and learners' characteristics, and regards design/selection of rational assessment means, teaching methods and technical tools as the core to create an autonomous, cooperative and exploratory learning mode, improve learners' learning initiative and effectiveness, cultivate learners' autonomous learning ability, knowledge application ability and technical exploration ability and facilitate learners' ability training and development. In the teaching theory, assessment means, teaching methods and technical tools are an inseparable whole. Assessment means and teaching methods are the important basis for choosing technical tools which provide conditions for assessment means and teaching methods.

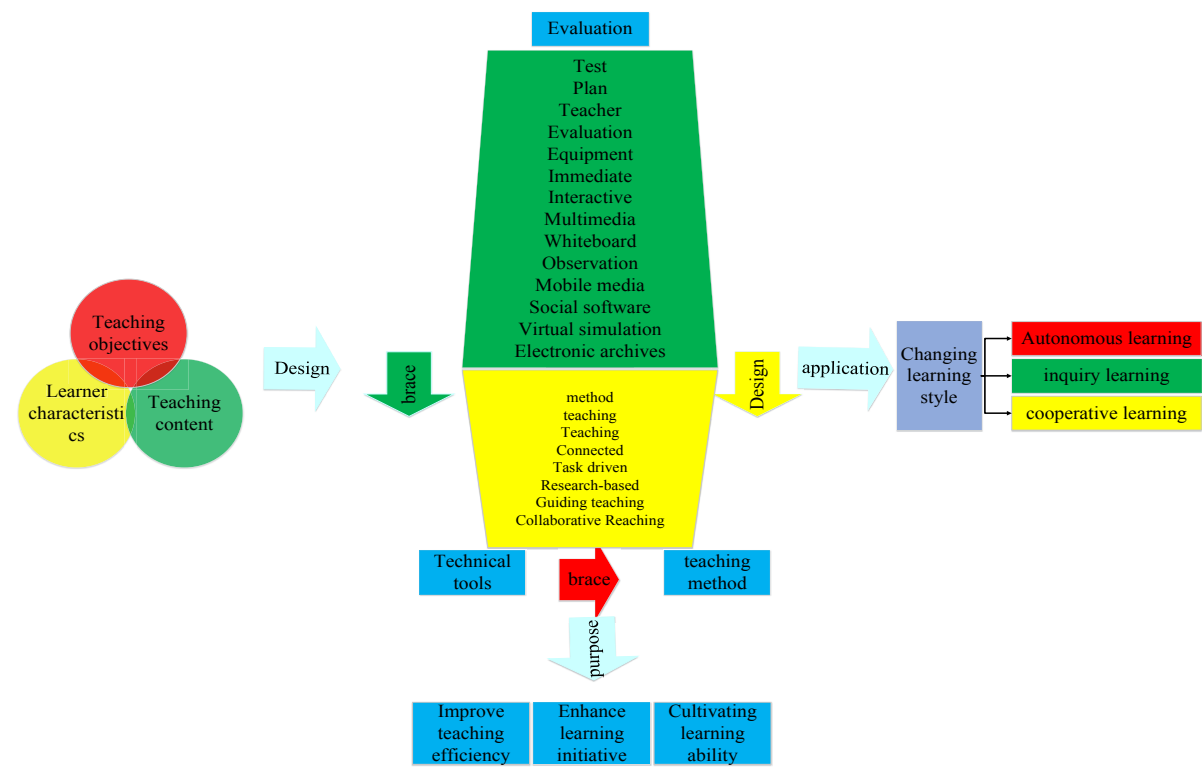

Fig. 2. Framework of APT teaching theory

\section{Mobile Multimedia Classroom Construction for Rhythmic Gymnastics Based on APT Teaching Theory}

With the development of information technology and network technology, mobile multimedia classroom is a high-end form which combines m-learning and network teachers, and it makes the classroom digitalized. The research and development of mobile multimedia classroom contribute to improving learners' learning ability. As shown in Fig.2, mobile multimedia classroom construction for Rhythmic Gymnastics based on APT teaching theory should start from three dimensions, i.e. assessment, pedagogy and technology. From the basic structure of APT (assessment, pedagogy and technology), a mobile multimedia classroom based on APT theory was built in this design. The mobile multimedia classroom regards learners as the fore to fully 
mobilize learners' initiative and provides learners with a learning platform which is different from traditional teaching and is not limited to time and place. Learners can learn freely in this mobile multimedia classroom and improve learning efficiency.

\subsection{Pedagogy design}

Pedagogy mainly refers to diversified teaching methods. From the perspective of learners, pedagogy was mainly designed from 5 aspects during constructing the mobile multimedia classroom, i.e. learner demand analysis, learner analysis, teaching objective setting, teaching content design, and learning activity design. In the course of Rhythmic Gymnastics, learners' demand is to master imitation ability, music feeling ability, art expressive force and movement coordination ability. The key point is that learners should comprehend the essentials of movements and cooperate according to their own conditions. Our research objects are the students of music and art major. So, learners' music feeling ability and art expressive force are strong. But, they still feel difficult to implement highly difficult movements. Thus, animation design for movement skills should be regarded as the key point in the design. The teaching content is rich and easy to understand. The teaching objective of Rhythmic Gymnastics is knowledge, technology and ability. Based on theoretical knowledge teaching, vivid and visual movement animation is provided. The teaching content of Rhythmic Gymnastics is decided by the teacher who arranges the detailed course content in accordance with students' ability and level. Task form may be applied in learning activity design. Learners may be asked to review the knowledge. This design mainly involves two learning activities: questions and answers between the teacher and students, and learning result presentation. The learning activity design can make students grasp the essentials of movements on the basis of understanding theoretical knowledge.

\subsection{Assessment}

Assessment means is refers to assessment of learners' learning effect. During considering learners' actual situation in the course of Rhythmic Gymnastics and constructing the mobile multimedia classroom, the assessment was mainly designed from 6 aspects, i.e. test, assessment gauge, taking notes and introspection, work display and exchange, peer assessment and teacher assessment. The test questions can feed back learners' learning effect in time. In this design, choice questions and true or false questions were adopted. The test results fed back correct answers in time and learners' learning achievements were recorded. The gauge was designed for learning achievement display activity. The gauge makes the standards from the standard degree of movement skills. The assessment is mainly given by the teacher. Taking notes and introspection are the methods of self-assessment. There is a note module for students, in which students can label knowledge content and essentials of movements. Learners carry out imitations according to the specified movement task, and upload the works in the form of video. The partners can assess learners' works. Two kinds of teacher assessment modes were applied in this design, i.e. email sending and sole 
training. Sole training means the teachers can appoint a student on the platform and carry out instructional assessment for the learning situation.

Multivariable regression analysis method is applied for assessment. The multivariable linear regression model is constructed according to the assumed conditions, least squares estimator and Gauss-Markov theorem.

$$
y_{t}=\beta_{0}+\beta_{1} x_{t 1}+\beta_{2} x_{t 2}+\mathrm{L}+\beta_{k-1} x_{k-1}+u_{t}
$$

Wherein, ${ }_{t}$ is the explained variable (dependent variable); $x_{t j}$ is explanatory variable; ${ }^{u_{t}}$ is random error term; $\beta_{0}, \beta_{1}, \ldots, \beta_{k-1}$ are regression parameters (unknown usually). The nonrandom expression is

$$
E\left(Y \mid X_{1 i}, X_{2 i}, \ldots X_{k i}\right)=\beta_{0}+\beta_{1} X_{1 i}+\beta_{2} X_{2 i}+\ldots+\beta_{k} X_{k i}
$$

$\beta_{j}$ is also called partial regression coefficient.

\subsection{Technology}

Technology provides conditions for pedagogy and assessment means. Technology has strong functionality. Only under the support of technology, pedagogy and assessment means can be achieved. During constructing the mobile multimedia classroom, the technology was mainly designed from 5 aspects, i.e. technical tool, technical support, technical availability, artistry and media property. The form of mobile multimedia is software app form. The hardware environment for its application is mobile terminal such as mobile devices with network connection function including smartphone and tablet personal computer. Operating instructions and setting for technical support explanation are shown in the homepage. Technical availability is mainly implemented from four aspects: functional design, interactive design, structural design and navigation design. Artistry refers to interface design which is characterized by conciseness and beauty. This design involves abundant media types, such as picture, audio and animation. Besides, automatic marking making plug-in was applied in the design. It offers convenience for teachers to product highly difficult movement animation and improves production efficiency.

In functional design of technical availability, multiple human-computer interaction and human-human interaction functions are provided. Email, interactive test questions, camera and other functions are used. The email is used for the exchange among learners and between learners and teachers. Interactive test questions are used to test learners' mastery of theoretical knowledge. The camera is used to shoot work display video of learners and the works are uploaded on the platform. Interactive design is mainly used between students and learning contents, among learners, and between teachers and students. Structural design is reflected in the explanation of each knowledge point. Before the explanation of each knowledge point, there is preview module. Key knowledge and movements are equipped with important marks in course 
teaching process. After the course is over, there is after-class test part. Learners can learn through the complete system. Each page is equipped with navigation design which can make learners clearly know their learning position.

\subsection{Interface display of APT-based mobile multimedia classroom for Rhythmic Gymnastics}

The construction of mobile multimedia classroom is based on APT teaching theory. The login interface is shown in Fig.3. Teachers and learners have different login account numbers and passwords. The initial account password is allocated by the system, as shown in the figure. The login interface of mobile multimedia classroom is concise and beautiful.

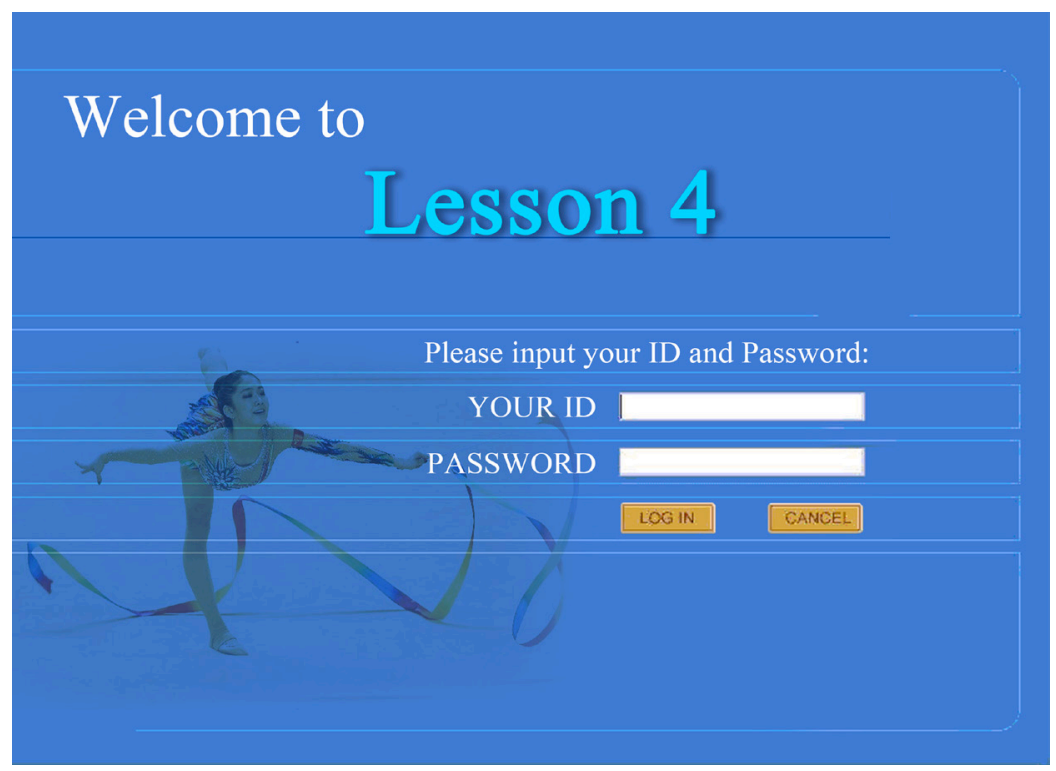

Fig. 3. The mobile multimedia interface of rhythmic gymnastics based on APT teaching theory

Teachers and learners have different login log-in interfaces. The teacher is responsible for modifying and supplying teaching resources as well as observing and recording students' learning conditions in time. After students $\log$ in, the navigation interface is shown in Fig.4. There are two modules in total: learning module and exchange module. Learning module includes four parts: before-class appraisal, learning task, notes and work display. Before-class appraisal is mainly used to test students' level before they learn new knowledge. The test results will influence the difficulty of knowledge. The learning task includes rich learning resources. All teaching contents are prepared elaborately by the teacher, with rich theoretical knowledge. The movement skills of rhythmic gymnastics are displayed by animation. These skills are made by the teacher through automatic animation marking. The animation is vivid and visu- 
al so that learners can well comprehend the essentials of movements. The learning task contains after-class test. Learners consolidate the knowledge through after-class test. The notes part provides learners a module to record and label personal learning difficulties. Learners can directly insert difficult knowledge points. In work display part, learners' gymnastic movement imitation is hot by the camera and uploaded in the form of works so that peers and teachers can assess the works. The exchange platform is used to achieve exchange and assessment between the teacher and learners and among learners. They can further learn and improve learning efficiency in mutual assessment.

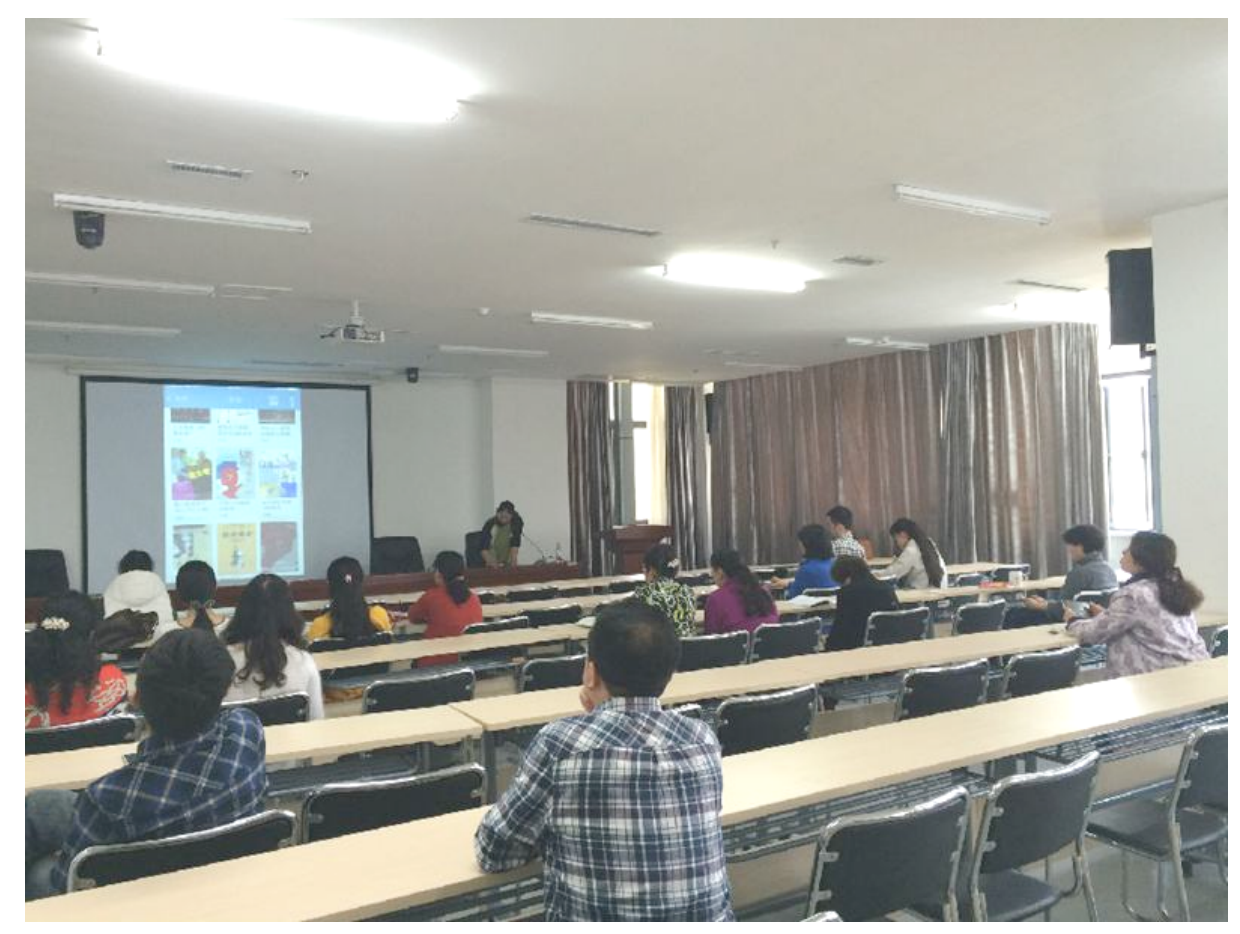

Fig. 4. Display of Mobile multimedia classroom

\subsection{Effect analysis}

To test the teaching effect of this mobile multimedia classroom for Rhythmic Gymnastics and compare teaching effects between traditional multimedia environment and mobile multimedia classroom, 50 students of music and art major in the same grade were chosen respectively as the objects of study. APT-based mobile multimedia classroom was applied for the experimental group. The teacher and students had applied the technology proficiently. Traditional multimedia teaching mode was adopted for the control group. The experimental results are shown in Table 1. 
Table 1. Scores of both groups in Rhythmic Gymnastics

\begin{tabular}{|l|c|c|c|c|}
\hline & $\mathbf{9 0 - 1 0 0}$ & $\mathbf{7 0 - 9 0}$ & $\mathbf{6 0 - 7 0}$ & Below 60 \\
\hline Experimental group $(\mathrm{n}=50)$ & 16 & 23 & 8 & 3 \\
\hline Control group $(\mathrm{n}=50)$ & 10 & 17 & 16 & 7 \\
\hline
\end{tabular}

${ }^{\wedge}$ It is known from Tab.1, the performance of students in the experimental group improves significantly. The number of students gaining 90-100 scores increases significantly, and the failure rate also declines significantly. This indicates that after the mobile multimedia classroom is adopted, students significantly enhance their mastery of knowledge and skills. The design of mobile multimedia classroom boosts students' learning efficiency.

The questionnaire survey was conducted for the 100 students, and the results are shown in Table 2, 48 students in the experimental group like the teaching mode of mobile multimedia classroom, in which 25 students like such teaching mode very much. 40 students in the control group like the teaching mode of mobile multimedia classroom, in which 30 students show their strong desire. Besides, they strongly yearn for such new teaching mode. Students tend to grasp the learning initiative, no longer limited to traditional classroom for knowledge and skill study.

Table 2. Questionnaire will comparison chart of both groups

\begin{tabular}{|l|c|c|c|c|}
\hline & Very like & Like & Commonly & Dislike \\
\hline Experimental group $(\mathrm{n}=50)$ & 25 & 23 & 2 & 0 \\
\hline Control group $(\mathrm{n}=50)$ & 30 & 10 & 6 & 4 \\
\hline
\end{tabular}

The above teaching experiment results show APT-based mobile multimedia classroom for Rhythmic Gymnastics has great attraction for learners. After the teaching experiment, learners' learning efficiency improves significantly. The mobile multimedia classroom gets rid of traditional multimedia teaching form. With the rapid development of information technology, learners can utilize existing mobile devices to learn knowledge freely, and be no longer limited to traditional classroom study. They may freely choose time and place. They grasp the learning initiative and greatly motivate their learning interest.

\section{Conclusions}

Assessment, Pedagogy and Technology are the key factors of effective teaching under information environment. In this paper, APT teaching model was proposed, and applied in teaching Rhythmic Gymnastics under mobile environment. Besides, automatic courseware marking making method was adopted. It is found that such new mobile multimedia teaching mode can greatly motivate students' learning interest, cultivate their learning initiative and improve teachers' animation production efficiency a lot. However, the new teaching mode was implemented in 2016, and it is still in the exploration stage. Teachers have some problems in the teaching process under 
multimedia environment, such as technical operation, classroom time control and teaching activity organization. The above defects need to be concerned and improved in the future. In conclusion, mobile multimedia classroom teaching is applied less in art teaching field. Based on rapid development of modern information technology, more in-depth researches are needed for mobile multimedia classroom.

\section{Acknowledgment}

This work was supported in part by the Humanities and social science research project of Ministry of Education (14YJC890026), Humanities and social science Key project of Anhui Education Department (SK2017A0188).

\section{$7 \quad$ References}

[1] Garcia-Cabot A, De-Marcos L, Garcia-Lopez E. An empirical study on m-learning adaptation: Learning performance and learning contexts[J]. Computers \& Education, 2015, 82(C):450-459. https://doi.org/10.1016/j.compedu.2014.12.007

[2] Liu, Y., Li, H., Carlsson, C. Factors driving the adoption of m-learning: An empirical study, Computers \& Education, 2010, vol. 55(3), pp. 1211-1219. https://doi.org/10.1016/ j.compedu.2010.05.018

[3] Purnomo, S.H., Lee, Y.H. E-learning adoption in the banking workplace in Indonesia: An empirical study, Information Development, 2013, vol. 29(2), pp. 138-153. https://doi.org/10.1177/0266666912448258

[4] Abualaish, A., Love, S. Factors Influencing Students' Acceptance of M-Learning: An Investigation in Higher Education, International Review of Research in Open \& Distance Learning, 2013, vol. 14(5), pp. 83-107.

[5] Anwar, M., Masud, H., Huang, X., et al. A Cloud Based M-learning Architecture for Higher Education, Archives Des Sciences Journal, 2013, vol. 66(1), pp. 751-1661.

[6] Evans, C. The effectiveness of m-learning in the form of podcast revision lectures in higher education, Computers \& Education, 2008, vol. 50(2), pp. 491-498. https://doi.org/10.1016/j.compedu.2007.09.016

[7] Cadavieco, J.F., Goulão, M.D.F., Costales, A.F. Using Augmented Reality and mLearning to Optimize Students Performance in Higher Education, Procedia - Social and Behavioral Sciences, 2012, vol. 46(2), pp. 2970-2977. https://oi.org/10.1016/ j.sbspro.2012.05.599

[8] Tian, L., Du, X.B. Mobile multimedia network foreign language teaching based on APP Technology, Course Education Research, 2015, vol. 20, pp. 99-100.

[9] Zhang, B. Design of mobile monitoring module of multimedia classroom based on Socket communication, Wireless internet technology, 2016, vol. 20, pp. 3-5.

[10] Xu, S. Exploration and thinking of art teaching reform in Universities, Journal of Jilin and TV university, 2012, vol. 9, pp. 131-133.

[11] Zhang, Y., Bai, Q., Li, X., et al. The Influence of Mobile Learning Based on the APT Teaching Model on Students' Learning Interest and Performance-a Case Study of Primary School Mathematics, China Educational Technology, 2016, vol. 24(1), pp. 26-33 


\section{Authors}

Youguo Shi is an associate professor in the Department of Physical Education and Art, BengBu Medical College, Bengbu 233030, Anhui, China. (e-mail: shiyouguo1234@yeah.net).

Shuqin Chen (corresponding author) is an assistant teacher in Department of art and design, Bengbu College, Bengbu 233030, China. (shiyouguo5886@163.com).

Haitao Wang is an associate professor in the Physical education institute, Huaibei Normal University, Huaibei 235000, China (wanghaitao2513@163.com).

Article submitted 03 April 2017. Published as resubmitted by the authors 11 June 2017. 